\title{
A case of Gastric Sleeve stricture resistant to endoscopic dilatation
}

\author{
Paritosh Gupta, Dhruv Kundra, Amanpriya Khanna, and Chinmay Arora
}

\begin{abstract}
Obesity is becoming an increasingly common disease across the world. Various restrictive and malabsorbptive surgical procedures have been developed to tackle morbid obesity. These procedures though efficient in causing weight loss and decrease in co - morbidities present with their own unique complications. Sleeve gastrectomy is one of the more recent, mainly restrictive procedure which has been gaining rapid popularity. Stricture of the gastric sleeve pouch is a rare and distressing complication of this procedure. Here we present a case of a 44-year-old woman who underwent Sleeve gastrectomy in Gulf 5 years back. She developed a stricture of the sleeve pouch for which she underwent two endoscopic dilatations which did not provide much relief. She was finally treated with a Roux - en - y gastro-jejunostomy which finally improved her symptoms.
\end{abstract}

Index Terms-Laparoscopic Sleeve Gastrectomy, Sleeve Stricture, Roux-En-Y Gastric Bypass.

\section{INTRODUCTION}

Obesity has become a common disease affecting people of both genders and all ages ${ }^{1}$. It's prevalence in females of Gulf countries ranges from $3-18 \%{ }^{2}$. Amongst all the surgical procedures for morbid obesity, Sleeve Gastrectomy has become very popular accounting for more than one third of all bariatric surgeries done worldwide ${ }^{3}$. This may be due the fact that sleeve gastrectomy is considered to be technically easier and safer than other bariatric surgeries ${ }^{4}$.

Stricture of the sleeve pouch have remained one of the distressing complication of this procedure whose ideal treatment is not yet standerdised ${ }^{5}$. There are various endoscopic and surgical options to Sleeve stricture with varying rates of success ${ }^{6}$.

Here we present a case of a 44-year-old woman who underwent Laparoscopic sleeve gastrectomy in Gulf 5 years ago. She developed progressive dysphagia over time and was diagnosed with a sleeve stricture. She had undergone two endoscopic dilatations for same which failed to provide any relief. She finally underwent a revision surgery where we converted the sleeve to a Roux -en - Y gastric bypass. Patient's progress post the revision surgery was satisfactory.

\section{CASE REPORT}

A 44-year-old female patient presented with history of progressive weight loss, intolerance to food and

Published on August 19, 2019.

Paritosh Gupta is with the Artemis Hospital, Gurugram, Haryana, India. (e-mail: paritoshg@artemishospitals.com).

Dhruv Kundra(corresponding author) is with the Artemis Hospital, Gurugram,Haryana, India.

(e-mail :drdhruvkundra@gmail.com) regurgitation following laparoscopic sleeve gastrectomy 5 years back. Her weight before the procedure was $128 \mathrm{kgs}$ which had reduced to $28 \mathrm{kgs}$ when she presented to us (Fig $1 \& 2)$.

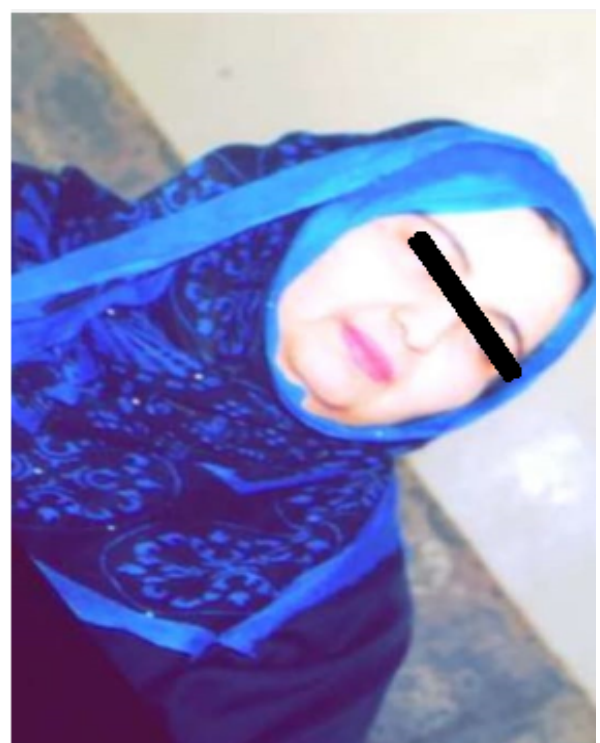

Fig 1 - Patient before she underwent Sleeve Gastrectomy (weight-128 Kgs)

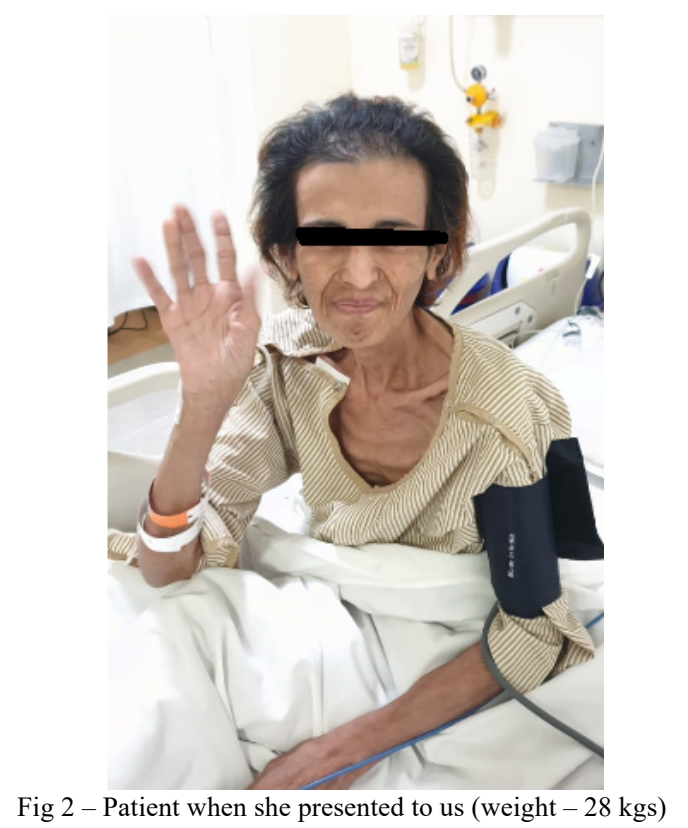

She underwent a barium swallow study 6 months after the surgery on which she was diagnosed with a stricture in the mid body region of sleeve (Fig 3). 


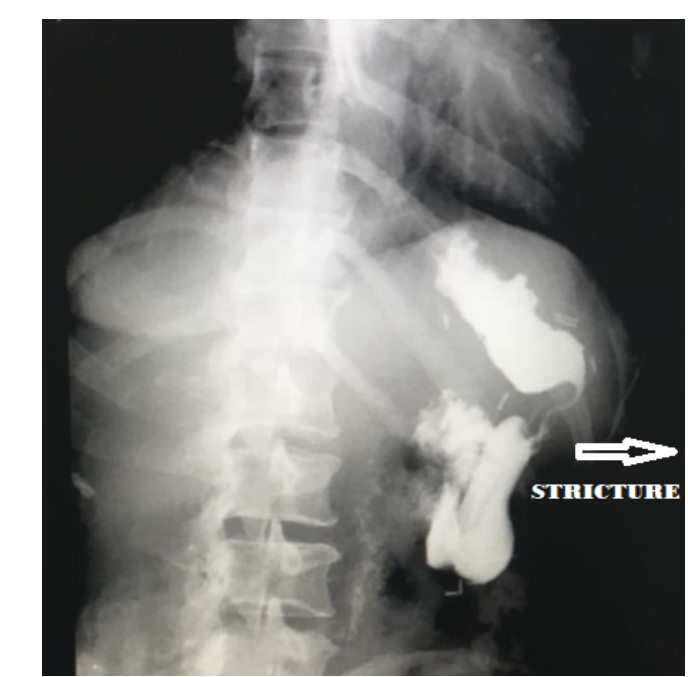

Fig 3 - Barium study showing sleeve stricture in mid body region

She underwent endoscopic dilatation twice, which provided temporary relief but her symptoms continued to worsen over time. She started losing her teeth, her hairs thinned out and her nails became brittle.

When she presented to us, her haematological workup revealed severe hypoalbuminemia. A decision was made to first perform a feeding jejunostomy to correct malnutrition before definitive revision surgery.

Post feeding jejunostomy and high protein high calorie diet, in one month her general condition and albumin levels improved.

Laparoscopic Roux-en-y gastric bypass was done with gastro-jejunostomy done at $50 \mathrm{cms}$ from dudeno-jejunal junction (Fig 4).

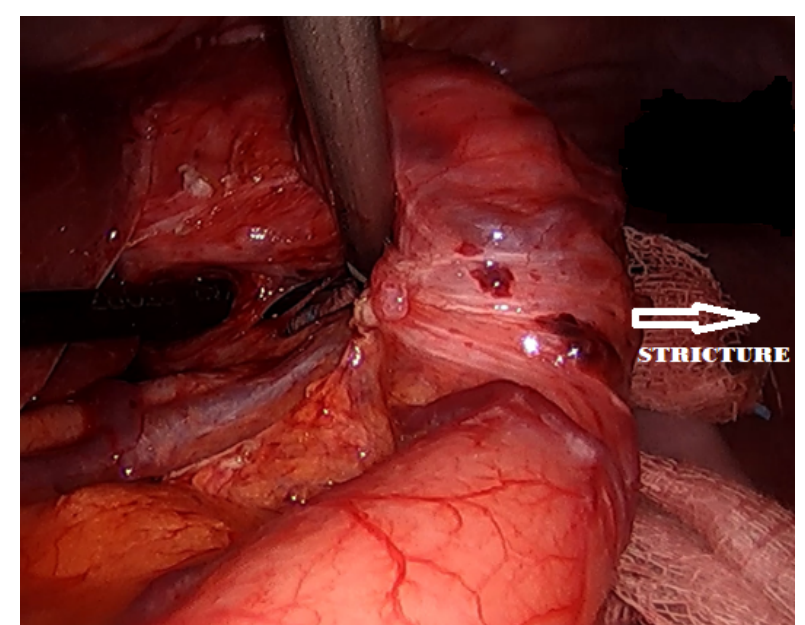

Fig 4 - Intra-operative picture showing sleeve stricture (white fibrous band)

Her recovery was uneventful and she was discharged on second post-operative day. On one month follow up she had gained $15 \mathrm{kgs}$ of weight and was able to accept normal oral $\operatorname{diet}$ (Fig 5).

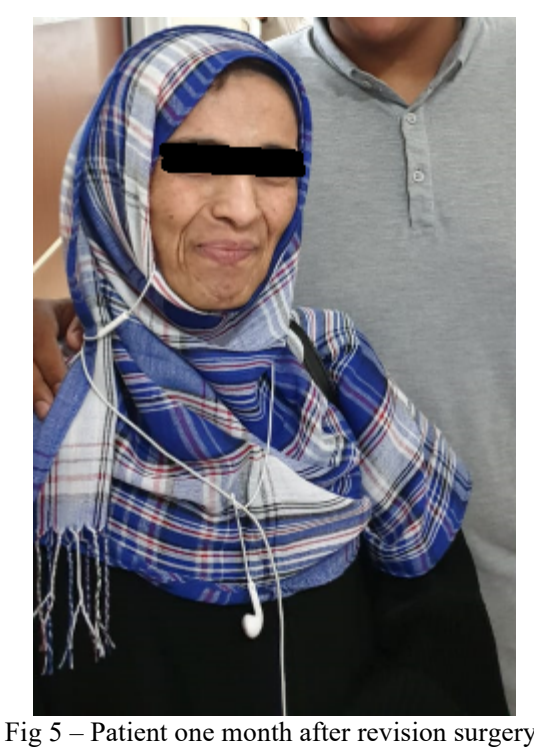

\section{DISCUSSION}

Stricture of sleeve pouch is an uncommon complication of sleeve gastrectomy procedure ${ }^{7}$. It's incidence ranges from $0.1-3.9 \%{ }^{3}$. These may present early within a month of a surgery or after that when these are called as late strictures ${ }^{8}$. Though it's not possible to point a specific cause for strictures, early strictures may be due to post-operative hematomas or oedema ${ }^{7}$. Late strictures are mostly due to surgical causes like excessive retraction, ischaemia or direction of staple line ${ }^{8}$. Patients present with complaints of dysphagia, vomiting, regurgitation and progressive weight loss ${ }^{7}$. In severe cases like the present one chronic malnutrition may also present with thinning of hair, loss of teeth and brittle nails.

Though most studies have identified Incisura of stomach as the most common site of sleeve stricture ${ }^{10}$, one study found "mid-body of sleeve" as site in more than half of all cases of stricture?.

Most of the early strictures can be managed conservatively with bowel rest and hydration. If there is no associated complication like abscess, they mostly resolve spontaneously $^{11}$. Late strictures require intervention. Endoscopic dilatation and use of stents are tried to manage these and are successful in most cases ${ }^{12}$.

In rare cases where endoscopic intervention fails such cases require revision surgery like conversion to Roux - en - y gastric bypass as in this case or gastro-gastrostomy where feasible. Surgical procedure depends on surgeon's expertise and judgement and there are no standard guidelines for management of sleeve strictures which do not resolve by endoscopic intervention ${ }^{12}$.

\section{CONCLUSION}

Sleeve stricture is a rare but troubling complication of sleeve gastrectomy whose early detection and optimal management can provide relief to patient. Endoscopic dilatation is usually effective but proper guidelines for treatment of cases refractory to endoscopic dilatation are not there. More such cases need to be studied to devise ideal protocols for its management. 


\section{ACKNOWLEDGMENT}

Authors thank Dr Rajesh Agarwal \& Dr Kanupriya for their assistance.

\section{REFERENCES}

[1] Francis DK.Fast-food and sweetened beverage consumption: association with overweight and high waist circumference in adolescents; Public Health Nutr. 2009 Aug;12(8):1106-14.

[2] Sultan ALNohair, Obesity in Gulf Countries. Int J Health Sci, 2014 Jan; 8(1): 79-83

[3] Angrisani L, Santonicola A, Iovino P, Formisano G, Buchwald H, Scopinaro N. Bariatric surgery worldwide 2013. Obes Surg. 2015;25(10):1822-32.

[4] Zellmer J, Mathiason M, Kallies K, Kothari S. Is laparoscopic sleeve gastrectomy a lower risk bariatric procedure compared with laparoscopic roux-en-Y gastric bypass? A meta-analysis. Am J Surg. 2014;208(6):903-10.

[5] Eubanks S, Edwards C, Fearing N, Ramaswamy A, de la Torre R, Thaler K, Miedema B, Scott J. Use of endoscopic stents to treat anastomotic complications after bariatric surgery. J Am Coll Surg. 2008;206(5):935-8.

[6] Dapri G, Cadière G, Himpens J. Laparoscopic Seromyotomy for long stenosis after sleeve gastrectomy with or without duodenal switch. Obes Surg. 2009; 19(4):495-9.

[7] Dhorepatil et al. BMC Surgery (2018) 18:52 https://doi.org/10.1186/s12893-018-0381-8

[8] Zundel N, Hernandez J, Neto M, Campos J. Strictures after laparoscopic sleeve gastrectomy. Surg Laparosc Endosc Percutan Tech. 2010;20(3):154-8.

[9] Shnell M, Fishman S, Eldar S, Goitein D, Santo E. Balloon dilatation for symptomatic gastric sleeve stricture. Gastrointest Endosc. 2014;79(3):521-4.

[10] Vilallonga R, Himpens J, van de Vrande S. Laparoscopic Management of Persistent Strictures after Laparoscopic Sleeve Gastrectomy. Obes Surg. 2013;23(10):1655-61.

[11] Sarkhosh, Kourosh et al. "Complications associated with laparoscopic sleeve gastrectomy for morbid obesity: a surgeon's guide." Canadian journal of surgery. Journal canadien de chirurgie vol. 56,5 (2013): 347-52.

[12] Parikh A, Alley JB, Peterson RM, et al. Management options for symptomatic stenosis after laparoscopic vertical sleeve gastrectomy in the morbidly obese. Surg Endosc. 2012; 26:738-46.

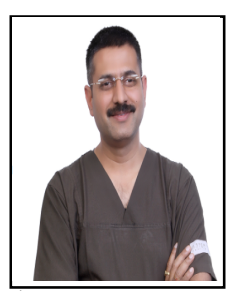

Dr Paritosh Gupta is a graduate from Sh. M P Shah medical college, Jamnagar, Gujarat and Post graduate MS (Surgery) from same medical college. He is a Board certified surgeon from National Board (DNB, Surgery). He has a prestigious Membership from National Academy of Medical Sciences.

He is currently Head of the Department, General, Minimal Access \& Bariatric Surgery at Artemis Hospitals, Gurgram, India. He has performed more than 10,000 successful surgeries is past two decades. He is a Trainer and Faculty at prestigious Ethicon Institute of Surgical Education, New Delhi. $\mathrm{He}$ is a teaching Faculty at Artemis Hospitals and is actively involved in training and teaching of DNB Postgraduate students \& FNB Fellows of Minimal Access Surgery. He is also faculty for FIAGES (Fellowship of Indian Associations of Gastro-Endoscopic Surgeons).He has been faculty and chairperson at various national and International surgical conferences

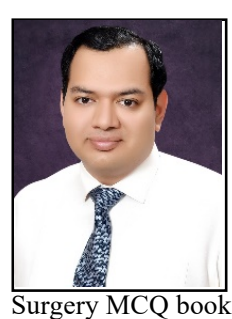

Dr Dhruv Kundra is a Fellow of Minimal Access Surgery at Artemis Hospital, Gurugram,India. He did his MS(Surgery) from Nagpur and previously worked at Government Hospital, Moti Nagar,New Delhi. He has made various presentations at national and International surgical conferences. $\mathrm{He}$ also has several publications in national and international journals.

$\mathrm{He}$ is co-author of a Minimal Access and Bariatric

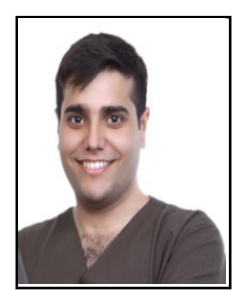

Dr Amanpriya Khanna is a senior registrar in department of Minimal Access and Bariatric surgery at Artemis Hospital,Gurugram.. He has made various presentations at national and International surgical conferences

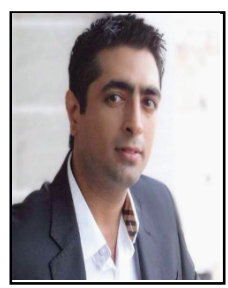

Dr Chinmay Arora is a DNB Surgery resident at Artemis Hospital,Gurugram 